\title{
High Dose and Low Dose Oxytocin Regimens as Determinants of Successful Labor Induction: A multicenter comparative study
}

\author{
MELESE GEZAHEGN TESEMMA ( $\nabla$ get.melese@gmail.com ) \\ Jimma University Medical Center https://orcid.org/0000-0003-0130-405X \\ Demisew Amenu Sori \\ Jimma University \\ Desta Hiko Gemeda \\ Jimma University
}

\section{Research article}

Keywords: Induction, high dose Oxytocin, low dose Oxytocin, successful induction, failed induction, Induction to delivery time.

Posted Date: December 17th, 2019

DOl: https://doi.org/10.21203/rs.2.17285/v2

License: (-) (1) This work is licensed under a Creative Commons Attribution 4.0 International License. Read Full License

Version of Record: A version of this preprint was published at BMC Pregnancy and Childbirth on April 21st, 2020. See the published version at https://doi.org/10.1186/s12884-020-02938-4. 


\section{Abstract}

Background: Induction of labor by Oxytocin is a routine obstetric procedure. However, little is known regarding the optimal dose of oxytocin so as to bring successful induction. This study was aimed at comparing the effects of high dose versus low dose oxytocin regimens on success of induction.

Methods: Hospital-based comparative cross-sectional study was conducted in four selected hospitals in Ethiopia from October 1, 2017 to May 30, 2018. A total of 216 pregnant women who undergo induction of labor at gestational age of 37 weeks and above were included. Data were entered into Epi-data version 3.1 and then exported to SPSS version 20 for cleaning and analysis. Chi-square test and logistic regression were done to look for determinants of successful induction. The result was presented using $95 \%$ confidence interval of crude and adjusted odds ratios. P-value $<0.05$ was used to declare statistical significance.

Result: The mean "Induction to delivery time" was 5.9 hours and 6.3 hours for participants who received high dose Oxytocin and low dose Oxytocin respectively. Higher successful induction (72.2\% versus $61.1 \%$ ) and lower Cesarean Section rate (27.8\% vs. 38.9$)$ were observed among participants who received low dose Oxytocin compared to high dose. Favourable bishop score [AOR $4.095 \% \mathrm{Cl} 1.9,8.5$ ], elective induction [AOR $0.295 \% \mathrm{Cl} 0.1,0.4$ ], performing artificial rupture of membrane [AOR $10.195 \% \mathrm{Cl} 3.2,32.2$ ], neonatal birth weight of $<4 \mathrm{Kg}$ [AOR 4.3, 95\% Cl 1.6, 11.6] and being parous [AOR $2.195 \% \mathrm{Cl} 1.1,4.0$ ] were significantly associated with success of induction.

Conclusions: In this study, Different oxytocin regimens didn't show significant association with success of induction. But, high dose oxytocin regimen was significantly associated with slightly shorter induction to delivery time. Favourable bishop score, emergency induction, performing artificial rupture of membrane and delivery to non-macrosomic fetuses were positive determinants of successful induction. We recommend researchers to conduct multicenter research on a large number of patients that controls confounders to see the real effects of different oxytocin regimens on success of labor induction.

\section{Introduction}

Induction of labor (IOL) refers to the iatrogenic stimulation of uterine contractions before the onset of spontaneous labor to accomplish vaginal delivery (VD) [1, 2]. Use of Oxytocin for labor induction is one of the most frequently used medications in obstetrics. This synthetic polypeptide hormone has been used to stimulate uterine contractions since 1950s after synthesized for the first time in 1953 by Vincent du Vigneaud [2-3].

Oxytocin regimen can be classified as high-dose or low-dose based on different parameters. These are amount of starting dose, rate of incremental dose and intervals of escalation $[4,5]$. The high-dose regimens varied across the different trials; starting doses ranged from 4-10 mili-unit/minute ( $\mathrm{mU} / \mathrm{min})$, with increases in dose ranging from 4-7 $\mathrm{mU} / \mathrm{min}$ and maximum rates ranging from 4-90 $\mathrm{mU} / \mathrm{min}$. The Low-dose regimen commences infusion at a range of $1-4 \mathrm{mU} / \mathrm{min}$, with rate increases ranging from 1-2 $\mathrm{mU} / \mathrm{min}$ and maximum rates ranging between 1-32 $\mathrm{mU} / \mathrm{min}$ as mentioned in one systematic review [4]. Intervals of escalation of oxytocin doses vary from 15 to 60 minutes across the trials [1, 4-12]. 
Worldwide, there was neither agreement on standard oxytocin regimen nor strong evidence to recommend a particular dosage of oxytocin regimen for labor induction $[5,12]$. However, one meta-analysis conducted in 1998 supports the use of a low-dose oxytocin infusion for IOL [3]. In Ethiopia, although very few studies were conducted to assess rate and determinants of induction success, there was no comparative study done to evaluate the effects of the two oxytocin regimens on success of induction. This study was, therefore aimed at comparing the effects of these oxytocin regimens on success of labor induction.

\section{Methods And Materials}

\section{Study area and study period}

Comparative cross-sectional study was conducted in 4 hospitals namely Jimma University Medical Centre (JUMC), Shanan Gibe general hospital, Arbaminch General Hospital and Kuyu General Hospital from October 1,2017 to May 30,2018. JUMC is the specialized teaching referral hospital where high dose oxytocin regimen was used for IOL while the three general hospitals used low dose oxytocin regimen.

\section{Study population}

Pregnant women with singleton gestations who undergo induction of labor at gestational age (GA) of 37 weeks and above were recruited. Pregnant mothers with Intra Uterine Fetal Death (IUFD), critically ill pregnant mothers, pregnant mothers with lethal congenital anomaly, pregnancies complicated by cord prolapse, induced pregnancy for whom cesarean section (CS) was done for non-obstetric indication like social reason were excluded from the study.

\section{Sample size \& sampling technique}

The required sample size was determined by using double population proportion considering the following parameters: Proportion of CS among laboring mothers who received high dose of oxytocin $(10.4 \%)$ and proportion of CS among laboring mothers who received low dose of oxytocin (25.7\%) [7], $5 \%$ level of significance, power of $80 \%$ and $1: 1$ ratio of exposed to un-exposed. Considering $10 \%$ for non-response, 108 laboring mothers were recruited for each group. Thus, 108 pregnant women were recruited from JUMC while the rest 108 (36 from each) pregnant women were recruited from three general hospitals. All pregnant women who had undergone induction of labor during study period were recruited consecutively using inclusion criteria.

\section{Data collection, entry and analysis}

Data were collected by trained midwifes using pretested structured questionnaire. Data like induction to delivery time, outcomes of induction (successful or failed), and mode of delivery, Oxytocin regimen, Bishop Scores and gestational age were collected from records of patient while socio - demographic data were collected by interviewing patients. 
Data were edited and entered into Epi data version 3.1 and then exported to SPSS version 20 for cleaning and analysis. Chi-square test was conducted to compare participants who received high dose oxytocin and low dose oxytocin in terms of outcome data (route of delivery and outcomes of induction). Bivariate and multivariable logistic regression analyses were conducted to identify determinants of the successful induction. Findings were presented using $95 \% \mathrm{Cls}$ of crude and adjusted odds ratios. P-value $<0.05$ was used to declare statistical significance.

\section{Ethical considerations}

Ethical clearance to conduct the research was obtained from institutional review board of Jimma University and written consent was obtained from study participants. All the information collected from the study participants were handled confidentially by omitting their personal identifiers and the data were used for the research purpose only. Participants were told by the language they understand that they have the right to participate in or withdraw from the study. In this research, the following operational definitions were used.

\section{Operational definitions}

- Successful Induction: If a woman delivered vaginally with or without aid of instrument after induction with oxytocin.

- Failed induction: If a woman deliver by CS due to failure to acquire either adequate uterine contraction ( $\geq 3$ contractions and duration lasting $\geq 40$ seconds in ten minutes period) or failed to show favorable cervical changes (reach at least $4 \mathrm{~cm}$ in dilatation and fully effaced) despite being on oxytocin drip for at least six to eight hours.

- Instrumental vaginal birth: When vaginal delivery is effected by either vacuum or obstetric forceps.

- Vaginal birth: Is vaginal delivery without any assistance by instruments like vacuum or forceps

- Induction to delivery time: The time it takes the mother from starting of oxytocin to delivery of the fetus either vaginally or abdominally.

- Low dose oxytocin regimen: Initial dose of $2 \mathrm{mu} / \mathrm{min}$ increased by $2 \mathrm{mU} / \mathrm{min}$ every 30 minute up to a maximum of $40 \mathrm{mU} /$ minute.

- High dose oxytocin regimen: Initial dose of $6 \mathrm{mu} / \mathrm{min}$ increased by $6 \mathrm{mU} / \mathrm{min}$ every 20 minute up to a maximum dose of $92 \mathrm{mu} / \mathrm{min}$.

- Favorable Bishop: Those Bishop score having value of greater than six

- Unfavorable Bishop: Those Bishop score having value of less or equal to six [2]

\section{Results}

\section{Socio-demographic, reproductive and obstetric characteristics of study participants}


A total of 216 pregnant women were participated in the study in four hospitals. Mean age of study participants and mean gestational age at delivery was 26 years and 39.4 weeks respectively. These distributions were similar among the two study groups. One third $78(36.1 \%)$ of the study participants were rural dwellers. Majority $176(82 \%)$ of the inductions were undergone on emergency basis. The top three indications for IOL in this study were premature rupture of membrane (PROM) 128 (59.3\%), hypertensive disorders of pregnancy (HDP) 49 (22.7\%) and post-term pregnancy 27 (12.5\%) while the others accounted for $12(5.6 \%)$. The indications for IOL were similar among the two study groups. Majorities of the participants enrolled in low dose group(LDG) 65(60.2\%) had favorable Bishop score at initiation of induction unlike those enrolled in high dose group (HDG) which was observed only in 14(13\%) (Table 1)

Table 1: Socio-demographic, Reproductive and Obstetric characteristics of the participants in four hospitals of Ethiopia

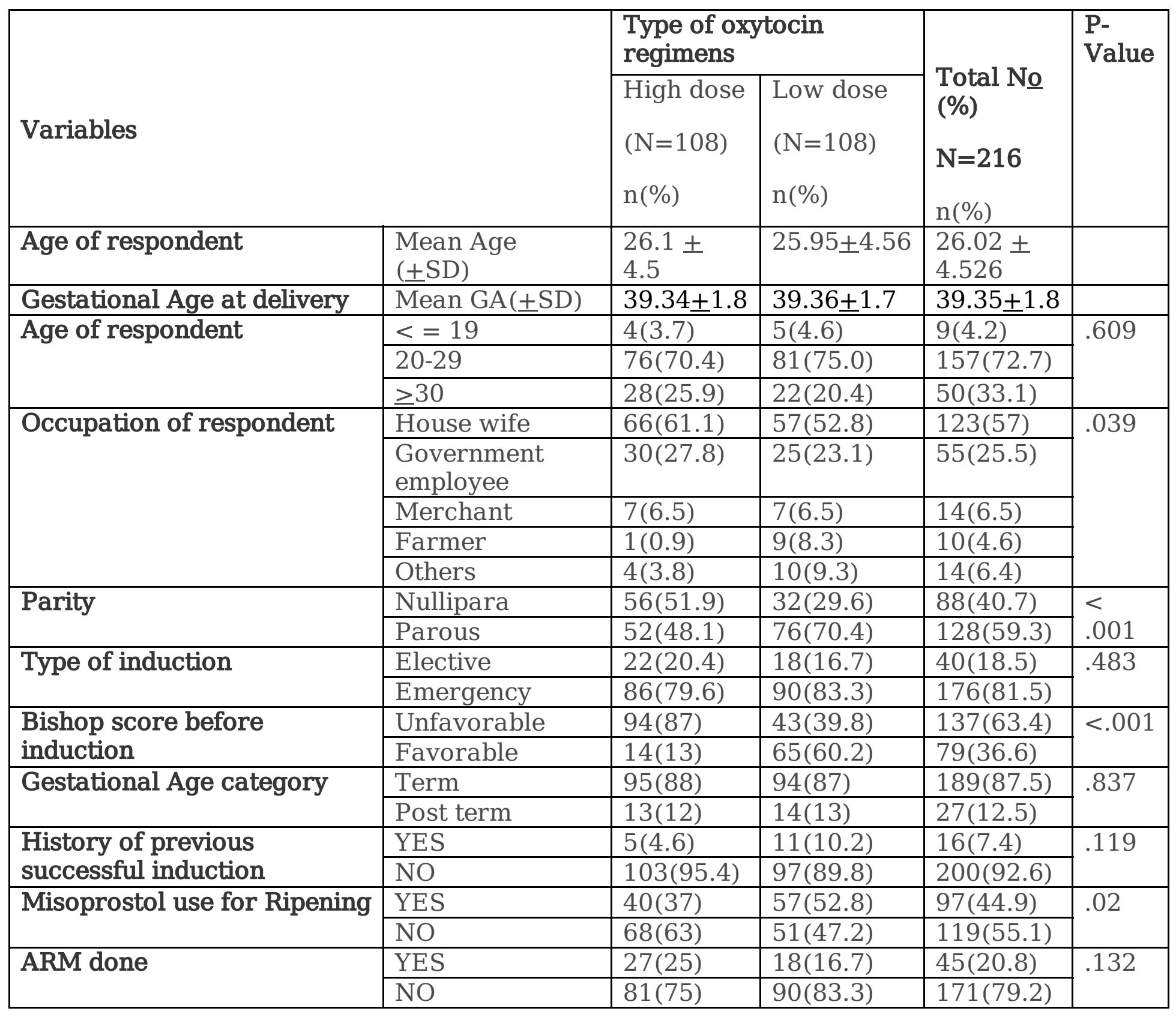




\section{Labor outcomes (induction to delivery time, mean oxytocin concentration, rate of CS, Rate of instrumental delivery, induction success)}

Mean induction to delivery time was 5.9 hours for HDG and 6.3 hours for LDG. Induction was successful in $61.1 \%$ and $72.2 \%$ of study participants among HDG and LDG while it was failed in $17.6 \%$ and $15.7 \%$ of mothers in the two groups respectively. Rates of instrumental delivery were $16(14.8 \%)$ and $5(4.6 \%)$ while that of CS were $42(38.8 \%)$ and $30(27.8 \%)$ among HDG and LDG respectively. Indications for CS in decreasing order were failed induction 19 (45\%), Non reassuring fetal heart rate patterns (NRFHRP) 19 (45\%) and CPD 4 (10\%) among HDG while they were failed induction 17(56.7\%), CPD 7(23.3\%) and NRFHRP 6(20\%) among LDG. NRFHRP as an indication of instrumental delivery was observed in $37.5 \%$ and $20 \%$ of participants enrolled in HDG and LDG respectively. Inadequate uterine contraction as a reason for failed induction was observed in $10 \%$ and $30 \%$ of HDG and LDG respectively (Table 2). Both successful induction (pvalue $=0.083$ ) and cesarean delivery ( $P$-value $=0.083$ ) didn't show significant relation with use of different oxytocin regimens. Only instrumental vaginal delivery $(P$-value $=0.012)$ and vaginal delivery $(P$-value $=0.002)$ had relation with use of different oxytocin regimens (Table 2).

Table 2: Outcome of pregnant women undergoing IOL with high dose and low dose oxytocin regimen in four hospitals of Ethiopia 


\begin{tabular}{|c|c|c|c|c|c|}
\hline \multirow[t]{2}{*}{ Variables } & \multirow[t]{2}{*}{ Categories } & \multicolumn{2}{|c|}{ Type of oxytocin regimen } & \multirow{2}{*}{$\begin{array}{l}\text { Total } \\
(\mathrm{N}=216)\end{array}$} & \multirow[b]{2}{*}{$\begin{array}{l}\text { P- } \\
\text { Value }\end{array}$} \\
\hline & & $\begin{array}{l}\text { High dose } \\
\mathrm{N}_{\mathrm{H}}=108\end{array}$ & $\begin{array}{l}\text { Low dose } \\
\left(N_{L}=108\right)\end{array}$ & & \\
\hline Induction to delivery time & $\begin{array}{l}\text { Mean duration (in } \\
\text { hours) }\end{array}$ & $5.9 \pm 1.8$ & $6.27 \pm 2.74$ & $6.07 \pm 2.32$ & \\
\hline $\begin{array}{l}\text { Maximum Oxytocin } \\
\text { concentration in } \mathrm{mu} / \mathrm{min}\end{array}$ & $\begin{array}{l}\text { Mean } \\
\text { concentration }\end{array}$ & $77.6 \pm 24.5$ & $22 \pm 12.5$ & $49.8 \pm 33.9$ & \\
\hline $\begin{array}{l}\text { Average length of } \\
\text { hospital stay in days }\end{array}$ & Mean duration & $2.0 \pm 1.5$ & $2.7 \pm 1.5$ & $2.4+1.6$ & \\
\hline \multirow[t]{2}{*}{$\begin{array}{l}\text { Reason for Failed } \\
\text { induction }\end{array}$} & $\begin{array}{l}\text { No cervical } \\
\text { change }\end{array}$ & 17(89.5) & 12(70.6) & $29(80.6)$ & \\
\hline & $\begin{array}{l}\text { Inadequate } \\
\text { Uterine } \\
\text { contraction }\end{array}$ & $2(10.5)$ & $5(29.4)$ & $7(19.4)$ & \\
\hline \multirow[t]{3}{*}{ Indication for CS } & $\begin{array}{l}\text { For failed } \\
\text { Induction }\end{array}$ & 19(17.6) & $17(15.7)$ & $36(16.6)$ & \\
\hline & For NRFHRP & 19(17.6) & $6(5.6)$ & $25(11.6)$ & \\
\hline & For CPD & $4(3.7)$ & $7(6.5)$ & $11(5.1)$ & \\
\hline \multirow[t]{3}{*}{$\begin{array}{l}\text { Indication for } \\
\text { Instrumental delivery }\end{array}$} & $\begin{array}{l}\text { For Shortening } \\
\text { SSOL }\end{array}$ & $7(6.5)$ & $4(3.7)$ & $11(5.1)$ & \\
\hline & For NRFHRP & $7(6.5)$ & $1(0.9)$ & $8(3.7)$ & \\
\hline & $\begin{array}{l}\text { For Prolonged } \\
\text { SSOL }\end{array}$ & $2(1.8)$ & $0(0)$ & $2(0.9)$ & \\
\hline \multirow[t]{3}{*}{ Mode of delivery } & VD & $50(46.3)$ & $73(67.6)$ & 123(56.9) & \multirow[t]{3}{*}{.002} \\
\hline & CS & $42(38.9)$ & $30(27.8)$ & $72(33.3)$ & \\
\hline & $\begin{array}{l}\text { Instrumental } \\
\text { delivery }\end{array}$ & $16(14.8)$ & $5(4.6)$ & $21(9.7)$ & \\
\hline \multirow{2}{*}{$\begin{array}{l}\text { Weight of neonate in } \\
\text { grams }\end{array}$} & $2500-3999$ & 103(95.4) & $89(82.4)$ & 192(88.9) & \multirow[t]{2}{*}{.002} \\
\hline & $\geq 4000$ & $5(4.6)$ & $19(17.6)$ & $24(11.1)$ & \\
\hline \multirow[t]{2}{*}{ Successful induction } & Yes & $66(61.1)$ & $78(72.2)$ & $144(66.7)$ & \multirow[t]{2}{*}{.083} \\
\hline & No & $42(38.9)$ & $30(27.8)$ & 72(33.3) & \\
\hline \multirow[t]{2}{*}{ Vaginal delivery } & Yes & $50(46.3)$ & $73(67.6)$ & & \multirow[t]{2}{*}{.002} \\
\hline & No & $58(53.7)$ & $35(32.4)$ & & \\
\hline \multirow{2}{*}{$\begin{array}{l}\text { Instrumental vaginal } \\
\text { Delivery }\end{array}$} & Yes & $16(14.8)$ & $5(4.6)$ & & \multirow[t]{2}{*}{.012} \\
\hline & No & $92(85.2)$ & 103(95.4) & & \\
\hline \multirow[t]{2}{*}{ C/S Delivery } & Yes & $42(38.9)$ & $30(27.8)$ & & \multirow[t]{2}{*}{.083} \\
\hline & No & $66(61.1)$ & $78(72.2)$ & & \\
\hline
\end{tabular}

\section{Factors affecting success of induction}

On Bivariate logistic regression analysis age, residence and family income of the respondent, previous history of successful induction, cervical ripening with misoprostol, type of oxytocin regimen, gestational age at delivery and neonatal weight did not show any kind of association with successful induction of labour. However, previous parity [COR $2.1,95 \% \mathrm{Cl} 1.2,3.7$ ], Bishop score at initiation of oxytocin [COR $3.4,95 \% \mathrm{Cl} 1.7$, 6.7], type of induction [COR $0.4,95 \% \mathrm{Cl} 0.2,0.7$ ] and performing ARM [COR 3.3, 95\% Cl 1.4, 7.9] were associated with successful IOL at P-Value $<0.05$. (Table 3 ). 
On multivariable logistic regression analysis, having favourable bishop score at initiation of oxytocin [AOR $4.0,95 \% \mathrm{Cl} 1.9,8.5$ ], elective type of induction [AOR $0.2,95 \% \mathrm{Cl} 0.1,0.4$ ], performing ARM [AOR 10.1,95\% $\mathrm{Cl} 3.2$, 32.2 ], neonatal weight of $<4000 \mathrm{gm}$ [AOR $4.3,95 \% \mathrm{Cl} 1.6,11.6$ ] and being parous [AOR 2.1, 95\% $\mathrm{Cl} 1.1,4.0$ ] were found to be statistically significant. (Table 3 ).

Table 3: Multivariate Logistic Regression of factors associated with success of induction in four hospitals of Ethiopa.

\begin{tabular}{|c|c|c|c|c|c|c|c|}
\hline \multirow[t]{2}{*}{ VARIABLES } & \multirow[t]{2}{*}{ RESPONSE } & \multicolumn{2}{|l|}{$\begin{array}{l}\text { Successful } \\
\text { Induction }\end{array}$} & \multirow[t]{2}{*}{ COR(95\%CI) } & \multirow[t]{2}{*}{$\begin{array}{l}\mathrm{P}- \\
\text { value }\end{array}$} & \multirow{2}{*}{$\begin{array}{l}\mathrm{AOR} \\
(95 \% \mathrm{CI})\end{array}$} & \multirow[t]{2}{*}{$\begin{array}{l}\mathrm{P}- \\
\text { Value }\end{array}$} \\
\hline & & Yes & No & & & & \\
\hline \multirow{3}{*}{$\begin{array}{l}\text { Age of } \\
\text { respondent } \\
\text { (in years) }\end{array}$} & $<=19$ & $4(44.4)$ & $5(55.6)$ & 1 & & 1 & \\
\hline & $20-29$ & $103(65.6)$ & $54(34.4)$ & $2.4(0.6,9.2)$ & .209 & $1.9(0.4,9.9)$ & .43 \\
\hline & $>30$ & $37(74)$ & $13(26)$ & $3.6(0.8,15.3)$ & .088 & $2.6(0.5,15.2)$ & .28 \\
\hline \multirow[t]{2}{*}{ Residence } & Urban & $87(63)$ & $51(37)$ & $0.6(0.3,1.2)$ & .134 & $0.6(0.3,1.29)$ & .19 \\
\hline & Rural & $57(73.1)$ & $21(26.9)$ & 1 & & 1 & \\
\hline \multirow{2}{*}{$\begin{array}{l}\text { Oxytocin } \\
\text { regimen }\end{array}$} & High dose & $66(61.1)$ & $42(38.9)$ & $0.6(0.3,1.1)$ & .084 & $0.6(0.3,1.53)$ & .29 \\
\hline & Low dose & $78(72.2)$ & $30(27.8)$ & 1 & & 1 & \\
\hline \multirow{2}{*}{$\begin{array}{l}\text { Previous } \\
\text { successful } \\
\text { induction }\end{array}$} & YES & $14(87.5)$ & $2(12.5)$ & $\begin{array}{l}3.8(0.8, \\
17.1)\end{array}$ & .085 & $1.6(0.3,9.02)$ & .58 \\
\hline & $\mathrm{NO}$ & $130(65)$ & $70(35)$ & 1 & & 1 & \\
\hline \multirow{2}{*}{$\begin{array}{l}\text { Gestational } \\
\text { age at } \\
\text { delivery }\end{array}$} & Term & $129(68.3)$ & $60(31.7)$ & $1.7(0.8,3.9)$ & .194 & $0.6(0.1,2.9)$ & .48 \\
\hline & Post-term & 15(55.6) & $12(44.4)$ & 1 & & 1 & \\
\hline \multirow{2}{*}{$\begin{array}{l}\text { Ripening } \\
\text { with } \\
\text { misoprostol }\end{array}$} & YES & $59(60.8)$ & $38(39.2)$ & $0.6(0.4,1.1)$ & .101 & $0.4(0.1,1.1)$ & .06 \\
\hline & NO & $85(71.4)$ & $34(28.6)$ & 1 & & & \\
\hline \multirow{2}{*}{$\begin{array}{l}\text { Previous } \\
\text { Parity }\end{array}$} & Parous & $94(73.4)$ & $34(26.6)$ & $2.1(1.2,3.7)$ & .012 & $2.1(1.1,4.0)$ & .024 \\
\hline & Nulliparous & $50(56.8)$ & $38(43.2)$ & 1 & & 1 & \\
\hline \multirow{2}{*}{$\begin{array}{l}\text { Bishop } \\
\text { score } \\
\text { before } \\
\text { induction }\end{array}$} & Favorable & $65(82.3)$ & $14(17.7)$ & $3.4(1.7,6.7)$ & .000 & $\begin{array}{l}4.1(2.0,8.8 \\
)\end{array}$ & .00 \\
\hline & Unfavorable & $79(57.7)$ & $58(42.3)$ & 1 & & 1 & \\
\hline \multirow{2}{*}{$\begin{array}{l}\text { Type of } \\
\text { induction }\end{array}$} & Elective & $19(47.5)$ & $21(52.5)$ & $0.4(0.2,0.7)$ & .005 & $0.2(0.1,0.5)$ & .001 \\
\hline & Emergency & $125(71)$ & $51(29)$ & 1 & & 1 & \\
\hline \multirow[t]{2}{*}{ ARM done } & YES & $38(84.4)$ & $7(15.6)$ & $3.3(1.4,7.9)$ & .006 & $\begin{array}{l}7.8(2.7, \\
22.6)\end{array}$ & .00 \\
\hline & NO & $106(73.6)$ & $65(90.3)$ & 1 & & 1 & \\
\hline \multirow{2}{*}{$\begin{array}{l}\text { Neonatal } \\
\text { weight in } \\
\text { gm }\end{array}$} & $<4000$ & $132(68.8)$ & $60(31.2)$ & $2.2(0.9,5.2)$ & .071 & $4.3(1.6,11.6)$ & .005 \\
\hline & $\geq 4000$ & $12(50)$ & $12(50)$ & 1 & & 1 & \\
\hline
\end{tabular}

\section{Discussion}

\section{Determinants of Successful Induction}


Being parous, having favorable Bishops score at initiation of oxytocin and performing ARM were significantly associated with increased success of induction by 2 times, 4 times and 8 times compared to nulliparous, unfavorable Bishop score and not performing ARM respectively. These results were in line with other study reports from Ethiopia [13-16]. This is because it is a well-established science that being parous, favorable cervical status and elective amniotomy or ARM were good predictors of successful induction of labor. Performing ARM strengthens the cascade of uterine contractions thus hastens labor and increase successful vaginal delivery. It was found that nulliparity had increased risk of failed induction by 1.5-3 times in other studies as well [13-14, 17-18].

Similarly, delivering to normal birth weight neonate compared to macrosomic neonate has increased success by 4 times. This might be justified by the fact that macrosomia is associated with labor dystocia and cephalopelvic disproportion thus ending in cesarean delivery. Our finding however, was not consistent with different literatures of the similar settings in Ethiopia that showed no association between neonatal birth weight outcome and induction success [13-14, 16].

However, induction on elective basis compared to induction on emergency basis has reduced the induction success by $80 \%$. This doesn't show association with failed induction in study conducted by Woubishet et al [13]. We expect successful induction of labor with elective induction than emergency induction. Because with elective induction one can buy time to ripen cervix till it gets favorable before initiating oxytocin thus increasing the success rate. But the finding of our study was opposite to this logic. This might be explained by the fact that majority of study participants (82\%) were induced on emergency basis. On other hand, of all remaining elective inductions, $68 \%$ were induced for post term pregnancy. Post term was associated with decreased induction success as seen in different literatures $[14,16]$.

\section{Labor Outcomes}

Success of induction was lower among HDG compared to LDG (61.1\% vs. $72.2 \%)$ while rate of CS was higher among HDG compared to LDG (38.8\% vs. $27.8 \%)$. These findings were consistent with one meta-analysis that showed higher CS rate among HDG [3] and one cohort study done at Inova Alexandria Hospital (28\% vs. $27 \%$ ) [5]. However, the finding of our study was in contrary to one Cochrane review (18.8 vs 19.8) [12], one double masked randomized oxytocin trial (11.3\% vs. $15 \%$ ) [9], and other two studies ( $9 \%$ vs. $12 \%)$ [19] \& (10.4\% vs. $25.8 \%$ ) [7] that showed higher CS rate among LDG. Although CS for failed induction occurred less frequently with the high-dose regimen ( $45.2 \%$ vs. $56.7 \%$ ), CS for NRFHRP was performed more frequently $(45.2 \%$ vs. $20 \%$ ) compared to LDG.

In this study higher successful induction and lower CS rate among LDG were observed compared to HDG. We can raise many possible explanations why these occurred unlike other studies. Firstly, $60 \%$ of participants in LDG had favorable Bishop Score compared to HDG (only 13\%) predicting higher successful induction and lower CS rate. Secondly, high dose oxytocin had statistically significant relation with NRFHRP in this study and mere occurrence of NRFHRP necessitating CS during labor might have reduced the possible number of successful vaginal deliveries if labor has to be continued. The fact that the number of mothers undergoing CS 
for NRFHRP among HDG was higher by 2.3 times than among the LDG (45\% vs. 20\%) may explain higher CS \& lower successful induction observed among HDG.

Thirdly, although not statistically significant in this study, higher utilization of misoprostol for cervical priming among LDG (52.3\% vs. 37\%), presence of higher proportion of mothers with previous history of successful induction (10.2\% vs. $4.6 \%$ ) and significantly lower proportion of nulliparous women in LDG (29.6\% vs. $51.9 \%)$ compared to HDG might have contributed to higher successful induction rate among LDG in our study.

Because misoprostol use was standard of management as it increases success of induction. Lastly, the fact that centers with low oxytocin regimen use oral misoprostol for cervical priming before oxytocin induction in contrary to high dose center which initiate direct oxytocin induction for prolonged PROM, and PROM being major indication of induction (60\%), might have contributed to higher induction success rate and thus lower CS rate among LDG .

Rate of failed induction was nearly the same among HDG (17.6\%) and LDG (15.7\%). This similarity in rate among the two groups was also seen in one cohort study comparing the two oxytocin regimen (4.3\% \& $5.1 \%)$ [5] and in one other double masked randomized oxytocin trial (6.0\% \& 6.1\%) [9]. However, rate of failed induction was generally higher in our study compared to those studies. This might be due to the fact that the studies were following different protocols in relation to total duration of hours waited to diagnose failed induction. In this study failure to acquire either adequate uterine contraction or failed to show favorable cervical changes despite being on oxytocin drip for a period of six to eight hours was used to diagnose failed induction. But other centers in literatures used to give more time ranging from 12 to 24 hours as latent phase can usually be prolonged but ended in vaginal delivery [1].

\section{Mean Induction to Delivery Time \& Mean Oxytocin to Vaginal Delivery}

Mean "Induction to delivery" time for study participants were 5.9 hours and 6.3 hours for participants of HDG and LDG respectively while mean time elapsed from initiation of oxytocin to vaginal Delivery were 5.1 hours and 6 hours among HDG and LDG respectively. Mothers receiving high dose oxytocin regimen had slightly shorter duration of labor. This finding was similar to many literatures although majority of them showed significant shortening of induction to delivery time (2-3 hours) compared to our study $[3,5,6,9,10,19]$. Similar effect was found when using oxytocin for augmentation [4]. This might be due to frequent escalation of oxytocin dose among HDG compared to LDG (every 20 minutes Vs 30 minutes) till getting adequate uterine contraction or favorable cervical outcome.

The limitation to this study was confounders like parity, Bishop score, cervical ripening agent \& fetal weight were not controlled so as to look the real effect of oxytocin regimen on induction success.

\section{Conclusion And Recommendation}

Oxytocin regimen didn't show any significant association with success of induction. But, high dose oxytocin regimen was significantly associated with slightly shorter induction to delivery time and higher utilization of 
instrument for delivery. Favourable bishop score, emergent type of induction, performing ARM and delivery to neonate weighing $<4 \mathrm{~kg}$ were positive determinants of successful induction. Thus we recommend that ripening cervix when condition allows, estimating fetal weight to exclude big baby and performing ARM before and during induction of labor. In addition we recommend researchers to conduct multicenter research on a large number of patients that controls confounders to see the real effect of different oxytocin regimens on induction success.

\section{Abbreviations}

AOR- Adjusted odds ratio; ARM: Artificial Rupture of Membranes; Cl: Confidence Intervals; CPD: Cephalo Pelvic Disproportion; COR: Crude odds ratio; CS: Caesarean Section; DPM: Drop Per Minute; HDG: High dose group; IOL: Induction of labor; JUMC: Jimma University Medical Centre; LDG: Low dose group; mu/min: Miliunit/minute; NRFHRP: Non reassuring fetal heart rate patterns; PROM: Premature rupture of membrane; SPSS: Statistical Package for Social Scientists; SSOL: Second stage of labor.

\section{Declarations}

\section{ACKNOWLEDGEMENT}

We would like to acknowledge the study participants for providing us the necessary personal information and Jimma University medical center for allowing us retrieve patients chart.

\section{AUTHOR'S CONTRIBUTIONS}

All authors participated in the design and analysis of the study. MGT searched the databases, and wrote the first and second draft of the article. DAS and DHG reviewed proposal development activities and each drafts of the result article. All authors revised the manuscript and approved the final version.

\section{FUNDING SOURCE}

There is no funding source for this research

\section{AVAILABILITY OF DATA:}

The data used to generate and or analyze the current study are available from the corresponding author upon the request.

\section{ETHICS APPROVAL AND CONSENT TO PARTICIPATE}

An official letter was obtained from the Institutional Review Board of Jimma University to conduct this research and get permission letter from the Hospital directors to collect data. Written informed consent was obtained from each study participant.

\section{CONSENT FOR PUBLICATION}

Not applicable for this publication. 


\section{COMPETING INTEREST}

We declare that we don't have competing interests with publication of this article.

\section{AUTHORS' INFORMATION}

1 Assistant professor, Arsi University, Department of Obstetrics and Gynecology, Asella, Ethiopia

2 Associate professor, Jimma University, Department of Obstetrics and Gynecology, Jimma, Ethiopia

3 Assistant professor, Jimma University , Department of Epidemiology, Jimma, Ethiopia

\section{References}

1. Deborah AW and Lili S. Abnormal Labor and Induction of Labor. In: Steven GG, Jennifer RN, Joe LS et al. Obstetrics: Normal and Problem Pregnancies, 7th edition.China: Philadelphia, PA: Elsevier, 2017: 276-283

2. American College of Obstetricians and Gynecologists (2009) Induction of labor. ACOG practice bulletin \#107. Obstetrics \& Gynecology, 114, 386-397. doi:10.1097/AOG.0b013e3181b48ef5

3. Joan M.G.Crane, David C. Young. Meta-Analysis of Low-Dose versus High-Dose Oxytocin for Labour Induction. Journal SOGC Nov 1998; 20( 13): 1215-23. Available at https://doi.org/10.1016/S08495831(16)31001-1

4. Wei SQ, Luo ZC, Qi HP, Xu H, Fraser WD. High-dose vs low-dose oxytocin for labor augmentation: a systematic review. Am J Obstet Gynecol. 2010 Oct;203(4):296-304. doi: 10.1016/j.ajog.2010.03.007. Epub 2010 May 8.

5. Alessandro G, Diann W, Victoria K, John CP, Sarah HP. Effects of two different protocols of oxytocin infusion for labor induction on obstetric outcomes:A cohort study. OJOG 2012, 2, 106-111 http://dx.doi.org/10.4236/ojog.2012.22020

6. Satin AJ, Hankins GD, Yeomans ER. A prospective study of two dosing regimens of oxytocin for the induction of labor in patients with unfavorable cervices. Am J Obstet Gynecol. 1991 Oct;165(4 Pt 1):9804. DOI: https://doi.org/10.1016/0002-9378(91)90453-X

7. Xenakis EM, Langer O, Piper JM, Conway D, Berkus MD. Low-dose versus high-dose oxytocin augmentation of labor-a randomized trial. Am J Obstet Gynecol 1995;173:1874-78.

8. Satin AJ, Leveno KJ, Sherman ML, Mclntire D. High-dose oxytocin: 20 versus 40-minute dosage interval. Obstet Gynecol. 1994 Feb ; 83 (2):234-38. Available at https://doi.org/10.1016/0091-2182(94)90138-4

9. Merrill DC, Zlatnik FJ. Randomized, double-masked comparison of oxytocin dosage in induction and augmentation of labor. Obstet Gynecol. 1999 Sep;94(3):455-63. DOI:10.1016/S0029-7844(99)80046-5

10. Frigoletto FD Jr, Lieberman E, Lang JM, Cohen A, Barss V, Ringer S, Datta S. A clinical trial of active management of labor. N Engl J Med 1995 Sept; 333:745-50 DOI:10.1056/NEJM199509213331201

11. Lopez-Zeno JA, Peaceman AM, Adashek JA, Socol ML. A controlled trial of a program for the active management of labor. N Engl J Med 1992;326:450-4.

12. Budden A, Chen LJY, Henry A. High-dose versus low-dose oxytocin infusion regimens for induction of labour at term.Cochrane Database of Systematic Reviews 2014, Issue 10. Art.No.:CD009701.DOI: 
10.1002/14651858.CD009701.pub2

13. Woubishet G, Fitsum T, Mirkuzie W. Outcome of Induction and Associated Factors among Term and PostTerm Mothers Managed at Jimma University Specialized Hospital: A Two Years' Retrospective Analysis. Ethiop J Health Sci. 2016 March; 26(2): 121-30. Available at http://dx.doi.org/10.4314/ejhs.v26i2.6

14. Hurissa BF, Geta M, Belachew T. Prevalence of Failed Induction of Labor and Associated Factors Among Women Delivered in Hawassa Public Health Facilities, Ethiopia, 2015. J Women's Health Care 4: 253. doi:10.4172/2167-0420.1000253

15. Berhan Y, Dwivedi AD . Currently used oxytocin regimen outcome measures at term \& postterm. II: Outcome indicators in relation to Bishop Score \& other covariates. Ethiop Med J. 2007;45(3):243-250.

16. Abdulkadir Y, Dejene A, Geremew MA, Dechasa B (2017). Induction of Labor Prevalence and Associated Factors for Its Outcome at Wolliso St. Luke, Catholic Hospital, South West Shewa, Oromia. Intern Med 2017; 7:5 doi:10.4172/2165-8048.1000255

17. Anggriani DD, Herawati L, Ernawati E. Parity as failure determinants of labor induction in Bangka Belitung. Majalah Obstetri \& Ginekologi, 2016; 24(3) : $79-83$.

http://dx.doi.org/10.20473/mog.V24I32016.79-83

18. Al-Shaikh GK, Wahabi HA, Fayed AA, Esmaeil SA, Al-Malki GA. Factors associated with successful induction of labor. Saudi Med J 2012; 33 (3):298-303

19. Satin AJ, Leveno KJ, Sherman ML, Brewster DS, Cunningham FG. High- versus low-dose oxytocin for labor stimulation. Obstet Gynecol. 1992 Jul; 80(1):111-6. 